\title{
ARTICLE
}

\section{Adolescent decision-making and the zone of parental control: a missed opportunity for legislative change ${ }^{\dagger}$}

\author{
Femi Akerele
}

\begin{abstract}
Femi Akerele is a consultant child and adolescent psychiatrist in Devon and an honorary university fellow at Plymouth University Peninsula Schools of Medicine and Dentistry. He has a special interest in medical law and medical education. He has recently completed a master's degree in medical law at Northumbria University. Correspondence Dr Femi Akerele, South Devon CAMHS, Lescaze Office, Shinners Bridge, Dartington, Totnes TQ9 6JE, UK. Email: femi. akerele@nhs.net
\end{abstract}

${ }^{\dagger}$ See commentary, pp. 151-152, this issue.

\section{SUMMARY \\ Issues relating to the consent of individuals under 18 years of age in England and Wales are covered by the Family Law Reform Act 1969, the Children Act 1989, the Mental Health Act 1983 (to some extent) and case law. Legislation on the consent of minors to hospital admission and treatment is complicated and contradictory, leaving clinicians unsure when to rely on the consent of the minor or that of someone with parental responsibility. This article reviews the concept of the zone of parental control (ZPC), introduced in England in 2008. It argues that this concept is too vague and subjec- tive to provide any clear guidance on who can give consent for a minor's admission and treatment. \\ LEARNING OBJECTIVES \\ - Understand the concept of the ZPC and its relevance to clinical practice. \\ - Determine the appropriate legal source of consent or refusal for children and young people. \\ - Consider using formal powers (as against parental consent) with children and young people refusing admission and/or treatment. \\ DECLARATION OF INTEREST \\ None.}

Current law in England and Wales dictates that the admission of a minor (anyone under 18 years of age) for treatment of mental disorder must either be with the consent of the young person or someone with parental responsibility, or comply with at least one set of legal safeguards. The choice of route for admission - informal or formal (Box 1) - will depend on a number of overlapping factors, such as:

- the age and maturity of the young person

- whether they are 'Gillick competent' (if under 16 years old) or have mental capacity (if over 16) for decision-making

- the consent of someone with parental responsibility

- the likelihood of deprivation of liberty.

Formal admission of any person (child or adult) under the Mental Health Act 1983 (MHA) does not require consent (except for admission under Section 3 of the Act, where consent of the nearest relative is necessary). However, consent is a relevant issue if the alternative routes are being considered, perhaps in an attempt to preserve a patient's autonomy or because of the perceived stigma of 'sectioning'.

Informal admission of anyone who has mental capacity is justified under Section 131 of the MHA. This refers to patients who are willingly agreeing and consenting to admission for treatment.

As established in case law (Re W (A Minor) 1992), consent to admission can be obtained from either the young person or someone with parental responsibility. Parental responsibility, as defined in the Children Act 1989, encompasses the 'rights, duties, powers, responsibilities and authority that parents have by law, in respect of their child and his or her property'. This parental power is, however, not unlimited and will depend on whether the child is under or over 16 years of age.

The evidence that over $65 \%$ of young people in in-patient units are informal patients (Mental Health Act Commission 2008) masks the reality that, for many of them, their detention is nonvoluntary and enforced under parental authority. With the 2007 amendments to the MHA and the publication of its Code of Practice the following year (Department of Health 2008), the current law states that a capable (as assessed under the Mental Capacity Act 2005 - the MCA) young

BOX 1 Routes for psychiatric admission of minors (individuals under 18)

- Informal (voluntary) admission:

- with the consent of the young person, or

- with parental consent

- Formal (compulsory) admission:

- under the Mental Health Act, or

- under the Mental Capacity Act, or

- by court authorisation 
person aged 16 or 17 can effectively consent to or refuse admission for treatment of mental disorder (MHA: Section 43). For those under 16, reliance on parental authority to sanction admission when the child is refusing is now discouraged.

\section{The zone of parental control}

The relatively new concept of the 'zone of parental control' (ZPC) was introduced in the revised MHA Code of Practice for England in 2008 (Department of Health 2008) but, significantly, not contained in the Code of Practice for Wales (Welsh Assembly Government 2008). Among the amendments to the MHA in 2007 were important changes with respect to children and young people which were reflected in the revised Code of Practice for England. In an attempt to formalise the guidance in relation to consent and the refusal of treatment by children and young people, the Code of Practice states that:

'People with parental responsibility may in certain circumstances [...] consent on behalf of a child under 16 to them being given medical treatment or being admitted informally for such treatment. Even in these circumstances, mental health professionals can rely on such consent only where it is within what in this guidance is called the "zone of parental control"' (Department of Health 2008: para. 36.9).

Although the term 'zone of parental control' may be new, the principle has been present in statute and case law for many years (Hewer $v$ Brant 1969), and the increasing autonomy given to minors in relation to consent has been discussed by a number of authors (e.g. Ford 2001; Shaw 2001; Paul 2004). It has been suggested that the introduction of the term is an attempt to formalise the increasing recognition of the importance of autonomy of mature minors (16and 17-year-olds) (Hawkins 2011). Interestingly, in departing from the guidance on parental rights to consent on behalf of capable minors refusing treatment contained in the 1999 version of the Code of Practice (Department of Health 1999), the revised code cites just one European case (Nielsen $\checkmark$ Denmark 1989) as its main influence. However, the 1999 guidance was consistent with the case law then in existence, especially $R e R$ [1992] and Re $W$ [1992], which gave parents rights to override their children's refusal of treatment.

\section{Nielsen v Denmark (1989)}

As mentioned above, the MHA Code of Practice cited the sole case of Nielsen $v$ Denmark as the basis for introducing the concept of the ZPC. This involved a 12-year-old boy, who applied (through his father) to the European Court of Human Rights, claiming infringement of his rights under Articles
5(1) and 5(4) of the European Convention on Human Rights. Following his parents' separation when he was 2 years old, the boy resided with his mother, who had parental responsibility under Danish law, although he maintained contact with his father. When he was 8 , he refused to return to live with his mother following a holiday with his father, and after numerous and convoluted legal processes, he was placed, with his mother's consent, in the psychiatric wing of a children's hospital. Although he had no diagnosed mental disorder, he spent over 5 months receiving 'environmental and talking therapy' in this hospital. It was not a locked in-patient unit, but its security was described as similar to locking the front door of the family home. Nielsen, however, claimed that he had been deprived of his liberty by his committal to the hospital and that, as this was the result of his mother's agreement, he was denied the opportunity to challenge the lawfulness of his detention before a court.

Narrowly, by nine votes to seven, the European Court held that Nielsen had not been deprived of his liberty under the European Convention as his admission to the hospital was decided on by his mother in exercise of her parental rights. The Court also did not believe that the mother, in exercising those rights, had infringed the child's rights as her objective was to protect her child's health. More importantly, the decision stated that 'the applicant was still at an age at which it would be normal for a decision to be made by a parent even against the wishes of the child'. However, the Court qualified this by accepting that the 'rights of the holder of parental authority cannot be unlimited and that it is incumbent on the state to provide safeguards against abuse' (Nielsen v Denmark 1989).

It is interesting that the Nielsen case did not directly examine the question of the boy's capacity to make a decision regarding his care and treatment, although he was clearly stating his wish to live with his father and he expressed dislike of the psychiatric unit.

\section{The ZPC as a safeguard against abuse of parental} authority?

It is possible that the ZPC is an attempt by the UK government to provide safeguards against the abuse of parental authority, as recommended in the Nielsen case. Even in that case, there were strong dissenting opinions by those who felt that the boy's committal to hospital was an abuse of both parental authority and normal psychiatric practice. The guidance given in the MHA Code of Practice for England is clearly at odds with the well-established case law of $\operatorname{Re} R$ and $\operatorname{Re} W$. 
Changes to the law of this magnitude would be expected to be introduced in statute rather than a code of practice, although it has been suggested that the government thought that detailed advice could be more readily provided in the Code, which is also easier to update (Bowers 2010).

But can this change be justified on the basis of an interpretation of just one decision by the European Court of Human Rights, especially when that case cannot be said to be particularly promoting the rights of the child? The relevance of the views of the young boy in the Nielsen case was not given significant attention, and the case can therefore be seen as a low point in the recognition of autonomous decision-making by minors. In the years that followed, there appears to have been a swing towards children's rights, especially those of mature minors.

\section{What is in the ZPC?}

The MHA Code of Practice gives no clear rules on what is within the ZPC and the guidance has therefore been described as vague, unhelpful and possibly harmful (Hewitt 2008). Instead, the Code provides two 'key questions' that must be considered by clinicians (Box 2). The National Institute for Mental Health in England (2009: para. 2.43) added a third consideration: "whether the parent has the capacity to make the decision in question'. The Code notes that the less confident clinicians are in saying 'yes' to the two key questions, the more likely it is that the decision is outside the ZPC. Let us look in more detail at the key questions and other considerations given in the Code.

BOX 2 What falls within the zone of parental control?

The Code of Practice advises clinicians to ask themselves:

1 whether the decision is one that a parent would be expected to make, bearing in mind both what is considered to be normal practice in our society and any relevant human rights decisions made by the courts, and

2 whether there are any indications that the parent might not act in the best interests of their child.

They should also consider:

- the nature and invasiveness of what is to be done to the child (including the extent to which their liberty will be curtailed) - the more extreme the intervention, the more likely it will be that it falls outside the zone

- whether the child is resisting - treating a child or young person who is resisting needs more justification.

(after Department of Health 2008: paras 36.10, 36.12)

\section{Is the decision one that a parent would be expected to make?}

This question will cover almost all decisions made by a parent in exercise of parental responsibility as defined by law (Children Act 1989: Section 3(1)). Surely, a parent's consent in agreement to a medical recommendation, despite a minor's refusal of it, would be considered 'normal practice'. If the doctor has recommended admission to hospital, and the parent consents to this, how can this be outside the ZPC? Or does this particularly apply to situations where parental views are in opposition to medical opinion? Even then, when such conflicts arise the existing law and guidance suggest recourse to the courts (Glass $v$ United Kingdom 2004), and the Code adds nothing new in this situation. The autonomous powers of the court are derived from its inherent jurisdiction, wardship and under statute.

\section{Is there any reason to believe that the parent might not act in the best interests of the child?}

The second question rightly considers the possibility that the parent's interests conflict with the best interests of the child. But this places an added and unwelcome responsibility on the clinician of 'judging' the parent's wishes, as well as determining the best interests of the child. It seems more likely that a parent's view will be deemed not in the child's best interests if it is not in agreement with the clinician's opinion. Also, as Hewitt (2008) argues, a parent's decision may fall within the ZPC, but may be contrary to the child's best interests. For example, in the Nielsen case, one can argue that the mother's consent, while within the ZPC, was not in the boy's best interests, as was subsequently determined in the Danish Supreme Court, which awarded custody to the father.

\section{Other considerations}

In determining what lies within the ZPC, clinicians are also asked to consider the nature and invasiveness of what is to be done and whether the child is resisting. The more extreme the intervention, the more likely it will fall outside the ZPC, and treating a child against their will is likely to need greater justification.

The ambiguous and confusing nature of this advice is worrying. What would fall within the definition of 'invasive'? The use of physical intervention in psychiatric units is well regarded as a critical and necessary part of therapeutic provisions, especially in managing agitation and aggressive behaviour. Interpreting para. 36.12 of the MHA Code of Practice, physical restraint 
to protect the child or others from harm may be deemed invasive and thus fall outside the ZPC. Although such 'invasive' actions can be carried out in emergencies 'in the best interests' of the patient, it is unclear how many times this could occur before falling outside the ZPC. Is the Code also suggesting that using intramuscular injection to administer medication to alleviate distress in a 16-year-old falls outside the ZPC? This is all unclear. Given that it is unlikely that young people in this situation would consent to such intervention, this could result in the increased use of compulsory powers of detention and treatment under statutory provisions.

\section{6- and 17-year-olds}

The Code includes separate guidance on the informal admission and treatment of 16 - and 17-year-olds. However, some of it does seem rather contradictory:

'A young person who has capacity to consent (within the meaning of the MCA) may nonetheless not be capable of consenting in a particular case, for example because they are overwhelmed by the implications of the relevant decision' (para. 36.28).

How can one have capacity yet be 'incapable' of giving consent? It is recognised that a person may possess capacity to make some decisions but not others, hence the recommendation that capacity should be assessed at the time a decision has to be made (General Medical Council 2008). Capacity to consent is not permanent: it is subject to change, can fluctuate and can be lost at any time.

Likewise, para. 36.23 states:

'Section 131 [of the MHA] also applies to a patient who is 16 or 17 years old and has capacity but does not consent (for whatever reason, including being overwhelmed by the implications of the decision) or who refuses consent, so in these circumstances a person with parental responsibility cannot consent on their behalf [...].'

That someone who has capacity may not be consenting because they are 'overwhelmed' by the decision is baffling. A person who is so overwhelmed surely could not be deemed to be capable, under the Mental Capacity Act 2005, as they would be "unable [...] to use or weigh that information as part of the process of making the decision' (MCA: part 1, para. 3).

The excuse given in the Code, that 'so much depends on the particular facts of each case' (para. 36.9), cannot be a valid reason for not devising clearer rules. The likely outcome is that clinicians will apply different rules depending on individual cases. It is exactly for this reason that I believe the law needs to be clearer and should not depend entirely on individual cases. The test for capacity is
BOX 3 Admission and treatment of minors under 16 years of age

- A young person can give consent to admission and treatment

- Refusal can be overridden by parental consent only if within the zone of parental control

- If the patient is refusing, it is unwise to rely on parental consent

- If the patient is refusing, it is preferable to use the Mental Health Act or court authorisation

- If not Gillick competent, parental consent can only be used if within the zone of parental control

(after Department of Health 2008)

standard and is applied to all patients, irrespective of age or purpose of treatment (Re C 1994). Surely, it is not unreasonable to expect clearer guidance.

\section{Implications for clinical practice}

Boxes 3 and 4 provide a summary of the MHA Code of Practice guidance on the ZPC as it applies to the under-16s and to 16- and 17-year-olds. This guidance, however well intentioned, is vague and too subjective to be helpful to clinicians (Bowers 2010). Previously, clinicians could rely on parental

BOX 4 The admission and treatment of 16 and 17-year-olds

\section{Admission}

- A young person can consent to and refuse admission

- Consent or refusal cannot be overridden by parental consent

- Refusal can only be overridden by a court or use of the Mental Health Act

- If the parents object to admission and the patient is refusing, court authorisation may be needed

- If the patient is incapable, parental consent can be used, but only if within the zone of parental control

- If the patient is incapable and the decision is outside the zone of parental control, it is preferable to use the Mental Health Act or court authorisation

Treatment

- A young person can give consent to treatment

- Refusal of treatment can be overridden

- If the patient is refusing, it is 'unwise' to rely on parental consent

- If the patient is refusing, it is preferable to use the Mental Health Act or court authorisation

(after Department of Health 2008) 
consent when a minor was refusing to consent to a proposed admission and/or treatment. Now, for admission and treatment of mental disorder at least (although the principle could be generalised), clinicians are advised not to rely on parental consent when a young person refuses. They are advised instead to consider using the MHA or seek authorisation from the courts. Thus, clinicians may end up in a situation where they have to use the MHA to admit and treat a young person who is refusing consent, even though the parents are in full agreement with the treatment plan. This has ethical implications, as well as the potential for stigma and damage to the future prospects of the young person. Furthermore, evidence suggests that there is marked and long-standing resistance among clinicians to the use of formal powers of compulsory admission and treatment of young patients (Department of Health 2001), meaning that doctors may have to undergo significant change in practice to fulfil the new legal requirements.

\section{Medico-legal concerns}

If compulsory powers under the MHA are not used and court authorisation is not obtained, clinicians may be open to professional disciplinary procedures or charges of criminal assault, especially when the treatment is outside the ill-defined ZPC. Patients could also claim infringement of their rights under Article 5 of the European Convention on Human Rights, if they are deprived of their liberty. As stated above, clinicians may well resort to increased use of the MHA, as opposed to reliance on parental consent, because of the Act's inherent safeguards.

What we have now is akin to two different laws concerning treatment, depending on what disorder the young person has. The MHA Code of Practice clearly has in mind admission and treatment for mental disorder, and not necessarily other forms of medical treatment. Thus, a capable 16- or 17-year-old can now effectively refuse admission and, possibly, treatment for mental disorder (MHA 1983: Section 131, as amended in 2007), but for all other medical (non-psychiatric) treatment their refusal may still be overridden by someone with parental responsibility (Family Law Reform Act 1969: Section 8(1); Re W 1992). One wonders whether mental disorder is now being given special consideration compared with other forms of medical illness. Why should a 17-yearold's refusal of informal admission for treatment of a psychiatric disorder be respected and effective, without the possibility that it can be overridden by parental consent, yet the same young person's refusal could be overridden by the parents if the admission were for treating an infectious disease? As the statute law remains unchanged, and in the absence of 'post-Human Rights Act' judgments in case law, 2007 amendments to the MHA were an opportunity for the government to amend the Family Law Reform Act 1969 to reflect the shift towards children's rights and autonomy, and devise clearer rules that cover all medical treatments.

\section{Increased use of compulsory detention?}

The advice contained in the MHA Code of Practice regarding the ZPC presents difficulties to healthcare professionals and the emphasis placed on the zone will have a significant impact on clinical practice. Barber et al (2009) suggest that it might result in a reduction in the reliance on parental consent even for incapable minors, and a corresponding increase in the use of compulsory powers of detention under the MHA. Indeed, this might be the main effect of the guidance offered in the Code, as healthcare professionals struggle to understand the extent of the legal rights of individuals with parental responsibility. However, Sandland (2010) suggests that it might not be a bad thing if more children were made subject to formal compulsory powers, with the added safeguards against unwarranted detention and treatment contained in the MHA. The alternative of 'compulsory informal admission' under parental consent without any particular safeguards is not appealing.

\section{When might the ZPC be relevant?}

It is worth noting that the ZPC is not the central issue many clinicians will face when making decisions on admitting or treating young people. Nonetheless it is very important. It would be relevant, for example, in any of the following situations:

- a young person is refusing admission or treatment, and cannot be detained under the MHA, but the parents give consent

- a young person lacks capacity and someone with parental responsibility consents on their behalf

- a young person already admitted and/or being treated with parental consent is now resisting admission or treatment

- physical restraint or intramuscular rapid tranquillisation are needed to manage a non-consenting or incapacitous informal young patient

- when there is doubt about the capacity of a parent to continue providing consent for a young person admitted under parental consent or for an incapacitous young person.

Some current medico-legal points relating to admission and treatment of young people are summarised in Box 5 . There is yet to be a challenge 
of the ZPC in the UK courts, although this might offer more clarity on the concept. It is therefore important that clinicians also remain up to date on related case law.

\section{Conclusions}

The government's adoption of a more cautious approach than is required in effecting a change in law is rather a missed opportunity. Initially, the draft Mental Health Bill 2004 included provisions recognising the need to safeguard children from inappropriate detention and treatment. However, the government decided not to amend the legislation, because it held that many of the questions could be adequately provided for in the MHA Code of Practice. The non-statutory nature of the resultant 'zone of parental control' has not offered healthcare professionals the necessary clear guidance as to the extent to which parental authority may be relied on, and it is more likely to confuse rather than enlighten clinicians.

The case law from the European Court of Human Rights to which the Code attributes the concept of the ZPC (Nielsen $v$ Denmark 1989) does not offer any insight into what is meant by the term either. In fact, the Nielsen case took a more expansive approach to the extent of parental control, in contrast to the Code of Practice's aim of limiting parental powers. Domestic case law probably provides a better source of evidence of the courts limiting parental powers and increasingly recognising child autonomy.

The fact that many professional and regulatory bodies have not issued or updated guidance to reflect the ZPC suggests that healthcare professionals are taking a cautious approach to the concept and are rightly observing the evolution of the law in this area. First steps in bringing together the key legal issues regarding admission and treatment of young people for mental disorder were published in 2009 (National Institute for Mental Health in England 2009; National Mental Health Development Unit 2009), and it will be interesting to observe how the development of case law in this area informs future guidance.

In light of increasing recognition of children's decision-making powers and autonomy, I believe that changes in law should be introduced through proper legislative scrutiny and debate, and not through the 'back door'. Furthermore, merely limiting parents' powers of consent on behalf of 16- and 17-year-olds is not far-reaching enough. The opportunity to introduce change in the law through statute to give these young people autonomous decision-making powers should have been seized. Providing greater clarity via legislation
BOX 5 Some medico-legal points relevant to decision-making in young people

\section{Consent}

- For consent to be valid (true consent), the young person must:

- have capacity to consent (or, if under 16, be Gillick competent)

- have sufficient information to make the decision

- act voluntarily and not under the influence of another person

- Consent can be implied or expressed (verbal or written)

- Valid consent is only needed from one source (young person, parents or court) for treatment to proceed

- Consent is not general but is specific to the treatment or intervention in question to change and can be withdrawn at any time

Who can hold parental responsibility?

- The birth mother has automatic parental responsibility

- Both parents, if married at time of the child's birth responsibility if they divorce

- Any other person, including an unmarried father, can acquire parental responsibility if conditions under Sections 4 and 5 of the Children Act are fulfilled

- Several people can concurrently have parental responsibility for a young person
- Consent is not permanent but subject

- Neither parent loses parental
- Anyone with parental responsibility may act unilaterally and independently, although not in a way that is incompatible with a court order or statute

- Local authorities may acquire parental responsibility under a care order or an emergency protection order

Capacity

- Is not an innate trait, but is acquired over time with growth and development

- Young people over 16 are presumed capable under the Mental Capacity Act

- Young people under 16 have to be proven Gillick competent for their consent to be valid

- Under the Mental Capacity Act, a person is unable to make a competent decision if they are unable to:

- understand relevant information

- retain that information

- use or weigh up that information

- communicate the decision

- Gillick competency depends on:

- the young person's maturity and understanding

- the nature of the treatment proposed

- the ability to reasonably assess the advantages and disadvantages of the treatment proposed

Gillick competency is defined in the ruling of Gillick $v$ West Norfolk and Wisbech Area Health Authority [1986] regarding the ZPC would be a starting point, but the preferable, proper and ambitious move should be statutory recognition of the decision-making autonomy of 16- and 17-year-olds.

\section{References}

Barber P, Martin D, Brown R (2009) Mental Health Law in England and Wales: A Guide for Mental Health Professionals. Learning Matters.

Bowers M, Dubicka B (2010) Legal dilemmas for clinicians involved in the care and treatment of children and young people with mental disorder. Child: Care, Health and Development, 362: 592-6.

Department of Health (1999) Code of Practice: Mental Health Act 1983. TSO (The Stationery Office).

Department of Health (2001) Seeking Consent: Working with Children. Department of Health

Department of Health (2008) Code of Practice: Mental Health Act 1983. Published Pursuant to Section 118 of the Act. TSO (The Stationery Office).
MCO answers

1 e 2 c 3 d 4 b 5 e 
Ford T, Kessel A (2001) Feeling the way: childhood mental illness and consent to admission and treatment. British Journal of Psychiatry, 179: 384-6.

General Medical Council (2008) Consent: Patients and Doctors Making Decisions Together. GMC.

Hawkins T, Player B, Curtice M (2011) The zone of parental control and decision-making in young people: legal derivation and influences. Advances in Psychiatric Treatment, 17: 220-6.

Hewitt D (2008) Too young to decide. Solicitors' Journal, 152 (37): 20-3.

Mental Health Act Commission (2008) Risk, Rights, Recovery: Twelfth Biennial Report 2005-2007. TSO (The Stationery Office).

National Institute for Mental Health in England (2009) The Legal Aspects of the Care and Treatment of Young Children with a Mental Disorder: A Guide for Professionals. Department of Health.

National Mental Health Development Unit (2009) Admission to Hospital and Treatment for Mental Disorder: Children under 16 Years Old. NMHDU (http://www.nmhdu.org.uk/silo/files/admission-to-hospital-and-treatme nt-for-mental-disorder.pdf)
Paul M (2004) Decision-making about children's mental health care: ethical challenges. Advances in Psychiatric Treatment, 10: 301-11.

Sandland R (2010) Children, mental disorder, and the law. In Principles of Mental Health Law and Policy (eds L Gostin, P Bartlett, P Fennell, et al): 655-98. Oxford University Press.

Shaw M (2001) Competence and consent to treatment in children and adolescents. Advances in Psychiatric Treatment, 7: 150-9.

Welsh Assembly Government (2008) Mental Health Act 1983: Code of Practice for Wales. TSO (The Stationery Office).

Gillick v West Norfolk and Wisbech Area Health Authority [1986] AC 112. Glass v United Kingdom (2004) 1 FLR 1019.

Hewer v Brant [1969] 3 WLR 425.

Nielsen v Denmark (App no 10929/84) (1989) 11 EHRR 175

Re C (Adult: Refusal of Treatment) [1994] 1 WLR 290 (FD).

Re R (A Minor) (Wardship: Consent to Treatment) [1992] Fam 11 CA.

Re W (A Minor) (Medical Treatment: Court's Jurisdiction)[1992] 3 WLR 758.

\section{MCQs}

Select the single best option for each question stem

\section{Which of the following is not a route of} admission for children?

a Mental Health Act 1983

b Court authorisation

c Parental consent

d The Mental Capacity Act 2005

e The Human Rights Act 1988

\section{A capable 16-year-old refusing admission} cannot be admitted via:

a Section 2 of the Mental Health Act

b Section 3 of the Mental Health Act

c parental consent

d court authorisation

e the Mental Capacity Act
3 The zone of parental control:

a aims to give parents more powers to consent on behalf of their children

$b$ is an Act of Parliament

c is a concept introduced in the Mental Health Act in 2007

d is guidance contained in the Mental Health Act Code of Practice for England

e lists the rights and powers parents have in controlling their children.

4 In deciding what is in the zone of parental control, clinicians are encouraged to consider:

a the age of the child

$b$ the nature and invasiveness of the intervention

c whether the child is refusing the intervention

$d$ the nature and degree of the illness

e whether both parents agree on the decision.
5 In introducing the zone of parental control, the Code of Practice cited the case of:

a Gillick v West Norfolk and Wisbech Area Health Authority

b Re R (A Minor) (Wardship: Consent to Treatment)

c Re W (A Minor) (Medical Treatment: Court's Jurisdiction)

d Glass v United Kingdom

e Nielsen v Denmark. 